\title{
Content Aggregation and Knowledge Sharing in a Personal Learning Environment: Serendipity in Open Online Networks
}

\author{
http://dx.doi.org/10.3991/ijet.v8iS1.2362
}

\author{
M. Saadatmand and K. Kumpulainen \\ University of Helsinki, Helsinki, Finland
}

\begin{abstract}
Web 2.0 tools and emerging technologies offer learners an abundance of information and resources. This brings more flexibility and choices for learners to better control their learning and benefit from the various available learning materials in different forms. This has resulted in new learning practices and environments in higher education which are more open, flexible, and studentcentered. Personal Learning Environment (PLE) is such a technology-mediated and learner-controlled learning environment. This paper describes PLE as a set of learnerdefined tools and services in the ecology of Web 2.0 used by participants in three open online courses. The aim of the study was to find out how participants create and utilize their PLEs for searching, aggregating, creating and sharing content and learning resources, and being engaged in online learning networks and communities. A particular interest was to explore how serendipity, as a by-product of these open online encounters, can occur. Data were gathered through an online survey, semi-structured interviews, and online artifacts. The findings suggest the serendipitous nature of content aggregation in a PLE and provide evidence of serendipity as a valuable and unexpected source for learning.
\end{abstract}

Index Terms - Content aggregation, MOOC, open courses, personal learning environment, serendipity.

\section{INTRODUCTION}

The rise of social media and networked technologies and the emergence of free/open software have influenced forms of communication and interaction in the current era. Such emerging technologies are becoming more commonplace in everyday life and especially in learning practices which can offer new learning opportunities at all levels of education, particularly in higher education. Technologies which enable distributed collaboration and global learning experiences challenge predominant pedagogical and offer the potential for 'pedagogical innovation' [1]. Such novel technologies offer new ways of learning, interaction and communication addressing the needs and requirements of web generations which demand new literacies and skills for learners in the twenty-first century.

With the advancement of Web 2.0 and yet other generations of Web (Semantic Web, Web 3.0, or Web X) [2] and their applications for learning, students can create and form learning spaces for themselves which are more personalized and learner-centered and give more flexibility and autonomy for them to control their learning.
In the area of technology-enhanced learning and online education, this has resulted in the development of discourses that address the departing from institutionalized learning systems to the more student-centered learning environments known as personal learning environments (PLE) [3] [4].

Personal learning environments, as understood in this paper, refer to a combination of social media-enabled systems, applications, and services which help learners to take control of their learning by aggregating, manipulating, and creating digital contents and learning artifacts, and sharing them with others. The nature of learning, information aggregation, content creation and sharing knowledge in such environments is different from traditional structured models. Students are surrounded by different tools and resources in different forms and repositories, and this abundance has influenced learning behavior to new and complete different ways [5]. Research on PLE and its conceptualization has gained interest in e-learning mainly after the emerging new generation of Web 2.0 technologies such as social networking tools, wikis, blogs, micro-blogging and social-bookmarking tools [3] [6] [9].

The research described in this paper investigated the nature of learning and interactions in open online courses in terms of online tools and services used by the participants. We explored participants' experiences, challenges and opportunities with online technologies in the process of learning, interaction, knowledge creation and sharing in three open online courses where various web 2.0 tools and social networking tools were deployed by instructors and learners. The purpose was to find out how participants of open online courses make use of tools like microblogging, social bookmarking, networking sites, and other free/open applications for seeking, aggregating, creating, and sharing content, and how all these activities and conditions may foster the processes of serendipitous discoveries.

\section{Changing The ConteXts for LeARning}

As long as learning and working environments are being transformed by a variety of emerging technologies, educational institutions are facing challenges in delivering their programs and courses. Technology brings new possibilities for learning, including changes in learning spaces and infrastructures, new ways of interaction and collaboration, and new demands for institutional regulations that adapt to better embrace these developments. Learning does not just take place inside the 
formal classroom with planned activities but, a growing interest towards mobile and ubiquitous learning and student-led activities outside the formal learning boundaries. This enhances learning experiences through exploration (by seeking and experiencing things in various contexts), interaction (through connection with peers and experts), and serendipity (searching for knowledge took place as by-product of the main task in unplanned and unexpected ways) [10].

Perhaps more than any time in history we have now access to more information, resources and networks which make our life more enriched in many ways. In addition to the benefits it may bring to us, the challenges are also notably to be considered in terms of schooling, learning and delivery of instruction [11]. "Interestingly, schools have tried to change. Pedagogy has offered alternative frameworks for approaching learning for generations, but the aspects of the traditional educational model that are premised in scarcity have proven deeply resilient and selfreplicating" (P.3).

Institutional change is an issue [12] in order to encompass these transformations, but so far there universities and educational institutions have not kept up with all these rapid technological opportunities to be innovative and more effective in their practices. We are not so much depending on classroom and teachers as the major sources of knowledge as it used to be, and we are no longer dependant on libraries in their traditional concept but rather on digital databases and online repositories. Although, these could be considered as resources and opportunities, they also bring challenges to the traditional notion and learning and instruction. So, there are some technological, pedagogical and cultural challenges embedded in today's learning practices that can require some alternatives in designing the curriculum, learning spaces, and other relevant infrastructures. Maybe one way looking at learning environments is that "there is a need for a shift from a monolithic learning environment in which everything must be controlled and predictable to a more pluralistic learning ecology in which both prescriptive and emergent application domains and modes of learning have their places" [12, p. 55].

With the fact that the level of engagement of higher education students in Web 2.0 and social networking tools is growing [13], and they have become more reliant on these pervasive technologies both in everyday life, learning and interaction, the relevant pedagogies should thus be tuned to the current trends and technologies [14]. Such pedagogies should make learning become more personalized, networked, and distributed [7] [15] [16] [17]. Recent and ever-growing transformations of learning environments signal for new pedagogical challenges and to the need for a paradigm shift from institutionalized learning environments to more personalized and flexible learner-centered learning spaces. The discourse about PLE is perhaps a response to these technological and pedagogical requirements that demonstrate a (not necessarily positive tension) between institutional control and learner autonomy.

\section{Personal LeArning EnVIRONMENTS}

Conversation and research on personal learning environments in the current definition based on the development and potential of Web 2.0 and emerging technologies is rather young and dates back to less than a decade ago. In 2005, Downes [4] referred to "E-learning 2.0 " to imply the affordances that web 2.0 tools and social media provide for more participatory learning. Since then, there has been attention about how to deploy these affordances to transform learning processes and environments and concerning the pedagogies needed to develop flexible, student-centered learning environments. Kop [18] explains that learning technologists started the research, design and development of personal learning environments that could include predictive technologies to help learners manage their learning in an open networked environment.

Although, there seems to be no common definition of PLE among researchers, especially from the point of view of learners, the notion of PLE is a metaphor that emerged from such endeavors to emphasize, on one hand, the learner's increased control of the learning process [19] [20] and for managing their own learning environment and, on the other hand, the potential of Web 2.0 technologies [4] [13] [15] [21]. The definition of PLE is based on the development of social software applications, Web 2.0 capabilities and a shift from the 'consumers' to 'prosumers' [20]. "PLE approach is concerned with changes from the learner's role in the process of learning, personalization of tools and resources, social engagement and self-organization of learning and technological aspects of social software tools and aggregation of multiple resources" (p.4). We agree with [7] on their definition of PLE that it is not only a personal space but also a social landscape that offers means to connect with other personal spaces in order to leverage knowledge within open and emergent knowledge ecologies which is open, distributed, diverse, emergent, and learnercontrolled.

PLEs have been of interest to many researchers, and developers of technology enhanced learning research have examined the technological and pedagogical considerations of such environments in order to conceptualize the innovative learning practices that are supported by the new emerging technologies (see [3] [5] [9] [13] [15] [19]). Anderson [22] has made distinctions between Learning Management System (LMS) and PLE and points out that PLEs allow for customization and personalization and interoperability among different applications which promote information flow. Personal learning environments are potentially promising such pedagogical approaches to connect informal and formal learning using social media which can support selfdirected learning. They are built on Web 2.0 tools and services and have the potential to help students aggregate, create, and share content and resources, participate in collective knowledge generation, and connect to wider global learning networks [19].

A concept that is close to PLE is Personal Learning Network (PLN). Many people may think these two terms have the same definition, but some researchers make a distinction between them. For instance Wheeler [23] describes PLE as a wider framework which encompass a personal learning network and 'personal web tools'. He defines PLN as people and groups with which we connect through social networks, but PLEs are wider and can include our experiences and learning through other tools, such as TV, radio, and print materials etc. Personal web tools in this framework are those usually web 2.0 tools which are used by a user to support lifelong learning. Mott 
[24] also sees PLN inside a PLE and states that institutions, teachers, and learners are increasingly turning to the open architecture and customizability of the web and leveraging the tools and resources of the larger PLE to create their own personal learning networks (PLNs). Mott further explains that whatever term we use, PLEs or PLNs, despite any distinction these approaches represent a shift from a model where students consume information to a model where students draw connections from a growing matrix of resources that they select and organize [24]. In this paper we do not tend to extend the argumentation about the distinction between PLE and PLN rather, as in [23] \& [44] we also see PLN as person's networks and connections and as a component of a PLE.

\section{ABUndANCE, SERENDIPITY AND LEARNING}

Technology is an enabler for bringing multiple opportunities of resources for learning, connections, and other forms of rich interactions that can promote and extend learning experiences in many ways. Arnold [25] utilized the metaphor "cabinet of curiosities" to point to the value of WWW as it provides great opportunities for learning and research. Being immersed in the abundance of web resources and repositories, creating and sharing knowledge in different platforms and connections, and communication by available online tools can bring unexpected and unplanned learning discoveries that might link to a meaningful learning. The abundance, diversity and connectivity make learning enriched and even in unprecedented ways when individuals are involved in diverse repositories and resources and connected to many networks and groups.

The resulting whole of these processes promotes the possibility of unexpected incidents that can be very valuable for them. This process of unplanned discoveries and interactions is so called "serendipity" [26] [27] [28]. We consider serendipity as valuable unexplored sources for learning which can be fostered through more connectivity and engagement by online tools and networks. Serendipity is not something new in the history of science and human creativity. Many important scientific discoveries have been made serendipitously. For instance, Fleming's discovery of Penicillin, Newton's theory of gravity, or Archimides' Bouncy Principle are such a cited serendipitous discoveries in the literature of science [26] [29].

The word serendipity was coined by Horace Walpole derived it from the Persian fairy tale 'The Three Princes of Serendip' (based on the life of Bahram Gur, king of Persia [ca. 418-38 A.D.] as described in Firdausi's epic Shahnamah [29]), whose heroes were always making discoveries by accidents [18]. Serendipity is defined as unexplored and unplanned discoveries and fortunate incidents in the process of exploring something else [26] [28] [30]. Buchem argues that serendipitous learning emphasizes the role of unexpected realization of hidden, seemingly unrelated connections or analogies for learning and research [26]. An important component of this would be sagacity as the ability to connect unconnected facts in coming to a valuable conclusion [27]. Buchem further discusses that surprising information and unexpected social relationships can lead to meaningful learning and enhance exploratory behavior:

The term 'serendipitous learning' has been used to refer to learning through gaining new insights, discovering interesting aspects and recognizing new relations which occur by chance. The idea of learning through exploration and discovery guided by a personal set of skills, interests and goals is of course not new and is closely related to a number of pedagogical approaches and learning theories, among others discovery learning (e.g. Bruner, 1961), exploratory learning (e.g. Riemann et al., 1996), experiential learning (e.g. Kolb, 1984), constructivist learning (e.g. Jonassen, 1991) and connectivism (e.g. Siemens, 2005) [26, pp. 2-3].

Bowles states that serendipitous learning identifies that searching for knowledge may happen as a by-product of the main task [28]. "For example, a search for information may launch the user off on a tangent that ends up being more productive than the original search query. In such instances serendipitous learning has taken place" (p.5).

Although Foster \& Ford [30] assert that serendipity is a difficult term to research and still is a relatively fuzzy concept but, it is important across disciplines especially in the literature of information retrieval and information seeking. We argue that in open online learning contexts where learners are involved in a variety of resources and activities, the processes of serendipitous learning are more probable and can be valuable for learners to open new directions and insights for their learning and interactions. Serendipity would seem to be important across disciplinary areas for its role in connection building, discovery and creativity. The literature of information seeking has also provided some support for the view of serendipity as a purposive or active phenomenon [30]. It is very likely in the process of information seeking on the web where people immerse themselves in the digital information spaces that a person comes up with some unexplored, incidental and yet valuable discoveries. It may result in the acquisition of new information or an idea related or not to a planned query which was the original intent of the user.

Downes [17] describes characteristics of learning in open networked environments such as MOOCs (Massive Open Online Courses) which are autonomy, diversity, openness, and connectedness. "Autonomy" allows learners maximum choice of where, when, how, with whom and even what to learn. They engage in diverse readings, discussions and environments. 'Openness' accommodates all levels of engagement, with no barriers between 'in' and 'out'. It helps to ensure the free flow of information through the network, and encourages a culture of sharing and a focus on knowledge creation. 'Connectedness' and interactivity is what makes all this possible” [31, p. 267].

In e-learning and online networking, there has been some research about serendipity; for example, the potential of micro-blogging tools like Twitter for fostering serendipitous learning [18] [32] [26]. Reinhardt, Wheeler and Ebner [32] found that Twitter is a potentially powerful social networking tool and users discover the serendipity of the service when they come across unexpected but extremely useful content that has been sent or re-tweeted by other users in their network. Kop [18] in a study of Twitter and RSS in open online courses (MOOCs) found that it seemed that the more participants have re-tweeted and used hash-tags and the more the number and spread of RSS feeds, the higher the likelihood of unexpected and challenging pieces of information and serendipity have been. She further argues that serendipity might be increased through communications with other people; and that the degree of serendipity may increase in learning 
network by the level of control over the information gathering process, the involvement of people, and the aggregation of information feeds [18].

Buchem [26] argues that the potential of incidental and serendipitous learning in social networks requires further conceptualization and more empirical research. In this study we elaborate on this topic of research and investigate the nature of serendipitous learning in open online networks in the context of MOOCs while participants are engaged in a variety of activities such as blogging, micro-blogging services, RSS, social bookmarking and many others.

\section{THE STUDY}

\section{A. Aim of the Study and RQs}

The aim of this study was to investigate how participants in open online courses use various Web 2.0 tools and services (defined as PLE in this paper) to search, aggregate, create, and share information and contents during the course. One particular interest was to find out how serendipity might occur in the abundance of information and resources. The following are the guiding research questions:

What constitutes a personal learning environment for the participants in open online courses?

- How is a personal learning environment utilized for seeking, aggregating, creating and sharing contents in open online courses?

- Is any serendipity taking place in the process of using various Web 2.0 tools and services and, if so, how?

\section{B. Research Setting, Participants and Data Collection}

This study is a qualitative ethnographic research which adapted online ethnography to discover the actual activities, learning experiences, and engagements of participants in open online courses. Online ethnography is a research methodology that focuses on the complexities of contemporary, technologically mediated social world [34]. Online ethnography has been used to study networking learning phenomena and technology mediated online practices [33] [35].

The empirical context of this study was open online courses known as Massive Open Online Courses (MOOCs) offered by some universities from Canada in 2010 and 2011. The courses were PLENK2010 (Personal Learning Environments, Networks and Knowledge; a 10weeks open course offered by Athabasca University), EC\&I831 (Social Media and Open Education; a 13-weeks open course offered by the University of Regina) and CCK11 (Connectivism and Connective Knowledge; a 12weeks open course offered by the University of Manitoba). The number of participants for each course varied from 150 to 1500 and from many countries around the world. Throughout all these three courses, Twitter activities, participants and facilitators' blogging, Facebook Groups and other social network interactions developed around the course subjects [18]. One central resource for the distribution of course materials was a Daily Newsletter that aggregated resources and artifacts produced by participants in their blogs, Twitter or wikis. The level of participation was varied from lurking to active participation. That was because these MOOCs were offered for a few numbers of for-credit students and the rest were taking part as non-credit participants. Those who were for-credit students were more active and supposed to produce some assignments but, other could have been participating in any extent the wish.

Participants of this study were from the three abovementioned MOOCs. Some of them had been already participating in other open courses and some other just participated in one of these MOOCs for the first time. Data were gathered by an online survey, online semistructured interviews, researcher's field notes, and online artifacts of the participants of the courses. After each course, a survey was carried out about the participants' activities and experiences during the course. Then twelve interviews were conducted each lasting from 45 to 80 minutes. Because participants were scattered in different countries, interviews were done and recorded online using Skype and Google Talk. Interviewees aged from 25 to 54 from six different counties. I interviewed both for-credit and not-for-credit participants. Online data included those kinds of contents that participants produced and shared on their blogs, Twitter, Facebook, YouTube, as their projects for the course and their reflections on their learning in the course. Interviews were transcribed and analyzed using qualitative analysis techniques.

\section{RESULTS}

In an earlier paper we have described the learning experiences and perceptions of participants in the open online courses in a broader scale in terms of managing their learning, general use of the online tools, and opportunities and challenges in such open networked learning environments [36]. In this paper we aimed to focus in more depth on the nature of content aggregation, creating and sharing knowledge and serendipity as a source for learning (all as defined in the previous discussion). These involve learning that happens in the open online courses we studied that had a large number of participants.

\section{A. Creating a PLE in Open Online Courses}

Earlier we discuss that the notion of PLE does not connote the same definition for all researchers, nor does it have the same meaning even to users. It depends on the situation, learning goals, personal preferences, and the student's level of technological competency. The latter seems to be crucial to how a PLE is created by a user. One participant answers that a PLE include: "The collection of tools that I use to process web-based information: includes Twitter, Tumblr, Google Reader, Flickr, Slideshare, email." Similarly another one explains it as "a range of tools to connect with people and resources and conversations you know ... I see my PLE as various technologies in terms of process and organization." The leverage of technology application and competency needed for developing a PLE as a hub for learning is another important issue: "My technological competency is pretty good, and the efficiency improves if I use the tool a lot." Thus, the level of competency and the frequency of using the tools influence how a PLE is developed. Because, for instance, this user had enough knowledge for using and applying tools in the process of learning, her PLE would be different and consists of many more tools than someone who does not know how to use a tool effectively. She further confides, "I wasn't that competent in those stuff, I was not that good user of them 
so, I didn't know them." This user goes on to reveal that, while she was not initially familiar with some tools, her competency in using the tools she needed for learning and communication had developed in connection with other users during the course.

PLE is an approach to student-centered learning which enhances a learner's autonomy and flexibility and the set of applications or tools can be varied depending on the user's choice and preferences, learning goals, and time. We understood from the participants' explanations that what is more important than just tools and concepts employed in a PLE is how the user can make sense of those tools and services and how to apply them in the process of learning and interaction. It does not necessarily just consist of Web 2.0 tools or a set of web based applications, but it can also include other traditional forms of media or any kind of means such as physical structures:

To me a PLE is just a jargon for the collection of tools and individual uses to organize resources in a web-based environment. If you extended its meaning, it would also include classrooms, television programs, hallway meetings, etc. As a collection of tools, PLEs have the characteristics of being controlled by the individual learner, and represent that individual's approach to material and social or professional.

PLE is not just a personal space but also a social landscape to promote various networking processes and to improve how a learner can personalize the sets of tools, services, and resources. So, various processes might be promoted through a PLE in open online learning that each tool can play a role for a process or a combination of processes through different interconnected applications. "PLE is a place where I share, gather, reflect, discuss, argue, and contemplate social media in education. I find that Twitter is the best to talk with people, discover new resources, read about what other people are doing." A personal learning environment is basically a networked hub for accessing, aggregating, creating, and sharing knowledge. It is a collection of tools and services defined and applied by a learner in the process of learning. In the realm of Web 2.0, a PLE usually could be a mash-up of free/open tools and applications defined and chosen by a user for specific learning purposes, maybe for a particular period of time and in a special context or circumstances.

My PLE is my browser in a general sense which I have set up many plug-ins and tools to keep updated with the information I am collecting and sending. A web platform which I use for aggregating the contents from blogs and websites I am subscribed.

Mash-ups are good solutions for developing a PLE on the enormity of Web 2.0 sphere for aggregating content (knowledge pull) to juxtapose content from different sources (e.g., feeds, widgets, media) into a single interface (mash-up for aggregation) [7] [21]. Fig. 1 illustrates a mash-up PLE that can contain an array of different (often connected) tools and services that a user builds using Web 2.0 potentialities. Tools and applications in such a personalized learning ecosystem could be connected through APIs (Application Programming Interfaces) and user-defined widgets in order to access content in diverse sources and aggregate them by different means. For example, social bookmarking tools such as Delicious and Diigo, RSS reader for getting updates of news and blog contents, micro-blogging tool such as twitter for sharing and receiving short messages are some components in a user-defined PLE. All these tools and services are defined by and between users. This figure only shows examples of the most popular and commonly used tools by users, but it could be different for each individual person according to needs and preferences. A user here explains how she fetches the tools she needs and for what purposes:

I use Twitter. I do not have college or personal contacts there. I use Facebook for real-life friends and people I meet in online classes. I use my Wordpress blog for communicating my own ideas and experiences in teaching, both online and on-site. Google Reader I use for reading blog posts, but it's so huge that I have trouble using it to store things, so I use Diigo for that. Twitter is part of my PLE but Facebook is not. I use Slideshare to share presentations from conferences and lectures from classes. I use Flickr to share photos related to work or classes I'm taking or teaching. I use Diigo to bookmark articles related to my work, and sources for my classes.

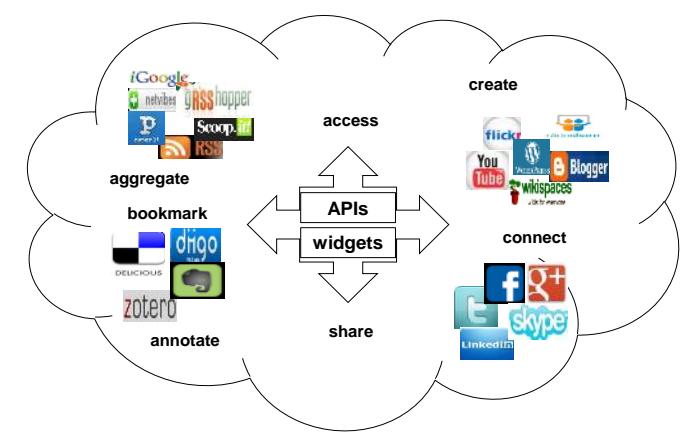

Figure 1. A mash-up PLE ecosystem

\section{B. Aggregation and Sharing in a Mash-up PLE}

Fig.1 convenes a range of processes for learning and interactions facilitated by different tools in a personal learning ecology [12] that enable the owner to aggregate content from different sources, remix, repurpose, and to create new content and share them through different tools. Mash-ups or blending together of spaces are reflective and collaborative spaces that students are becoming familiar with in online learning [21].

The ability to combine web tools; some blogs for example host live microblogging feeds (e.g. Twitter stream incorporated into Blogger) whilst others simply hyperlink to wikis or display 'blog rolls' - a list of links to other blogs the owner reads and recommends ... Really Simple Syndication (RSS) feeds for aggregating content which pushes or feeds notification of web page updates directly to the subscriber as they occur, usually to their e-mail account.(p.6)

In a mash-up, tools and services which are used as a PLE in the open online courses we studied foster the opportunities for serendipitous discoveries and coming up with new resources for learning. Fig. 2 shows different types of notifications, updates and activities in some tools in a PLE; for instance Google reader, Google Alerts, and social bookmarking tools Delicious and Diigo that bring resources and materials for the user. This approach of collecting different resources inside a PLE provides updates of the feeds and pulls them together in an easyaccessing way. Some of these resources are those the user has set to get new updates. For instance, Google Alerts can be set up for different topics and keywords of interest to gather related content for a keyword and bring them to the user at a defined interval schedule. As can be seen in figure 2, the Daily Newsletter has been one means of content aggregation used to send the updates and materials to the participants. In open courses like PLENK10 all of these feeds were harvested through a platform called 
gRSSHopper mediated by one of the course facilitators and sent everyday to the participants' emails (shown in Fig 2.). It was collecting all materials regarding the course which used the course \#hashtag whether in Twitter, blogs, or wikis. In another course Paper.li was used to syndicate contents using \#hash-tags or keywords to curate the content and deliver them to the participants in a daily base. There were many resources related to the subjects of the course in Diigo and Delicious that were collected and shared by the course participants and facilitators. All these ways of content aggregation and sharing provided participants with such valuable unexplored and unanticipated resources that they may not have been intending to use. With such an abundance of information the flow serendipity emerges and fortifies learning.

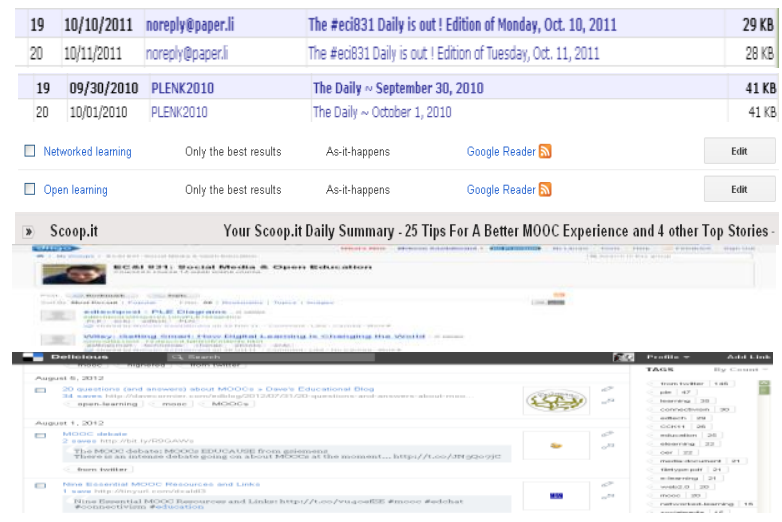

Figure 2. Aggregation and curation of materials in different tools

Some tools seem to have many more capabilities for fostering serendipity; for instance the RSS and microblogging tool Twitter have shown in previous research [18] [26] [32] to have great potential for users to bring valuable un-searched resources and new connections to people and networks. Fig 3. Shows TweetDeck, a desktop application for managing and aggregating feeds from various social networking tools such as Twitter, Facebook, Google Plus etc., which is a useful tool for updating feeds and monitoring the latest activities on different channels. When the application starts, in the notification area (right-hand side in Fig 3.), the activties that have happened and what have been shared in the channels the user is subscribed to are shown. It also shows the number of updates to each one of the hash-tags that the user is following. Employing an application like TweetDeck has been a useful way to connect with other people and getting new updates from them as a participant expressed her own use of it:

I have TweetDeck. I use Twitter because I connect with teacher in ESL in the whole world and we tweet things we have weekly discussions on. I attend one of the teacher's webinars because of Twitter, I mean that Twitter introduced me to many things in this world in my career as a teacher.

By reveiwing all these updates and notifications, a user can get into a veriety of resources and contents which have been circulated in different networks and by different individuals that might or might not necessarily ha e been originally followed by this user. This promotes the likelihood of receiving new materials that can have valuable new insights for the learner. Through these discoveries a person also develops new connections and locates new contacts. In such a dynamic and instant- updating space with numerous activities by many users, serendipty is likely to accur that can open up new ways of discovery for learner. Kop [27] in a study on MOOCs found that receiving re-tweets heightens serendipity because these tweets would be provided by contacts of contacts, yet still be reasonably close to the aggregator. Fig 4. demonstrates the number of tweets, retweets, and replies in one of the MOOCs of course related events and resources. These tweets have been what participants found interesting which can also contained serendipitous information in associated links [18].

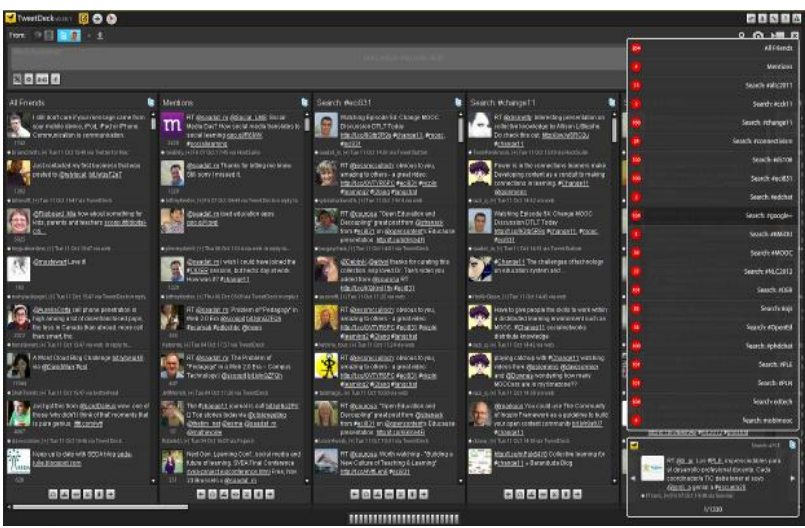

Figure 3. TweetDeck desktop application which shows notifications and latest updates

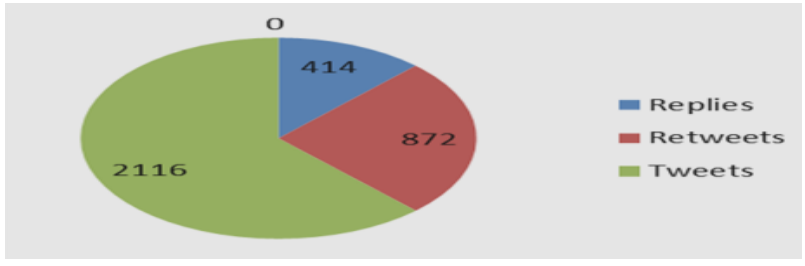

Figure 4. Tweeting in one of the MOOCs [18]

\section{Information Flow, Unexpected Connections and Fostering Serendipitous Learning}

The flow of information between various platforms and applications can prompt various sorts of serendipity for other users. In the abundance of information in which people find themselves, many serendipitous moments happen that can be more valuable than what was at first intended. This can bring new direction for learning and connect individuals to other valuable resources of which they are not otherwise aware. The ability of learners to connect unexpected and unplanned discoveries to their goals and planned purposes is a sagacious ability [27] that makes the connections richer. That is the value of networked learning that, in addition to planned goals for learning, creates the opportunities for fostering serendipitous moments. Such serendipitous discoveries and interactions are seen as exciting and meaningful, and it may generate new ideas, new connections and encourage further exploration that can lead to construction of new knowledge [26].

Jarche [37] refers to the process of 'seek-sense-share' to explain multiplicity and the overload of information to be leveraged in order to maximize use: how a user can search for information, make sense of it, and then share it. He then discusses how new ideas and insights can emerge from this process. The web is a big space for serendipity and in the realm of social web 2.0 and ubiquitous social 
technologies, searching for new information enables possibilities for further discoveries and developing connections that enhance chances of encountering different ideas and insights [26]. The power of social media brings possibilities for learners to pull together and share information. APIs and widget can support interconnectivity and allow for better opportunities for serendipity to happen.

In contrast to being "disciplined" and conservative, openness seems to play an important role in nurturing serendipity. "Openness extended to the point where the notion of 'discipline' could be a hindrance to serendipity" [30 p. 336]. Connectedness and interactivity (i.e. how a person is connected to different people, networks and communities) and diversity (i.e. how a person is using various tools and resources) are both also important factors in this regard [31]. When individuals engage in a diverse load of resources and materials available for them online through different repositories, when they are connected to many networks and groups, and when they are open to share their thoughts freely and openly with others, the whole of these processes promotes the possibility of unexplored incidents and unpredictable coincidences that we have described as serendipitous learning.

Among the four types of serendipity that Henry [38] describes, social serendipity, and crowd-sourced serendipity seem to be fostered through the tools and resources are utilized in a personal learning environment in open online courses (Fig 1.). Some of our content discovery nowadays comes from our social online networks; our friends, networks, and circles. Such examples are Facebook and Twitter which include friends and peers with possible common interests who may share relevant content that are useful for us. Social serendipity is something that some participants in open online courses have experienced as result of being connected and it involves the possibility of such open networked environments to bring people together.

I think that was the real strength of MOOC that the amount of emergent learning was huge and there was no way to predict what's been going to happen. The fact that I wouldn't be working with different people from different countries if there would not have been these connections in this course, that's the possibility with working online which is fantastic, you would never have got in any other way.

Another participant claimed that MOOC as an open learning environment enabled him to get some tools to use as parts of his PLE and to develop connection with other people:

I haven't been tweeting I opened up my Twitter account with open course PLENK10 and since then you know I am having a very good experience with Twitter, I really like twitter this is one of my top tools. I would say and I have got so many connections, I have got so many resources from the \#hash-tags in Twitter, also very interesting people who I haven't event known before and I haven't been familiar with their work.

With crowd-sourced serendipity social bookmarking tools such as Delicious, Diigo, Digg, etc., become spaces of discoveries [38]. In the MOOCs we have studied, some of these tools have been used by the participants for sharing contents related to their interest and pertinent to the course subjects (as shown in Fig 2).

\section{CONCLUSIONS}

In this paper we have presented some opportunities and challenges for participants in open online courses in dealing with the abundance of information, tools, and emerging technologies. The main purpose was to describe the nature of information aggregation, content creation and sharing, and interactions, and the value of serendipity as a source for learning in open networked learning environments such as MOOCs. In fact, we were interested in understanding how serendipitous discoveries can occur while learners immerse themselves in the abundance of digital content spaces and engage in various online networks and communities. With the emergence of open/free applications and social software, learning environments are becoming more distributed and easily accessed anytime and anywhere. Kop points out that, technologies are now available to empower learners to take control over the information flow and to be proactive in pursuit of valuable information. For learners to make the most of emerging technologies they need to take an active role in shaping their own learning environment and in controlling information stream and communication tools [27].

The concept of personal learning environment has been developed with the Web 2.0. The PLE approach as a learner-centered paradigm gives more attention to the role and autonomy of learners in the process of learning to create, develop and control their own personalized and customized learning spaces. PLE discourse is getting more attention in online education in relation to integrating informal and formal learning mediated by technological and social infrastructures.

In this paper we discussed some issues regarding the nature of content aggregation, learners' interactions, and opportunities for fostering learning through serendipitous discoveries in open online courses; MOOCs,. We observed serendipity and unexpected discoveries and connections as valuable sources for learning. The unpredictability of serendipitous learning makes it difficult to plan and to foresee its effects; yet some researchers claim that serendipity is not mere chance but it can also be designed in order to increase a person's chance of making fortunate discoveries [39]. Apart from a few studies on serendipity in online learning contexts [18] [26] [32], there is little research that explains how using open online tools and applications--for example microblogging such as Twitter and social bookmarking tools--may impact serendipity [18]. It is still an open agenda for further research to investigate the nature and real values of such incidental learning and unexplored discoveries. Also as [18] indicates, it is useful to examine how to increase serendipity in information flows and how it could be fostered and heightened in information streams to help learners in their personal self-directed online learning.

\section{REFERENCES}

[1] G. Conole, M. de Laat, T. Dillon, \& J. Darby, "Disruptive technologies, pedagogical innovation: What's new findings from an in-depth study of students' use and perception of technology." Computers \& Education, 50, 2008, pp. 511-524. 
[2] S. Wheeler, "The future of learning: web 2.0 and the smart extended web". LearnTEC, Karlsruhe, 2011. http://tinyurl.com/68beada [ Mar. 16, 2012].

[3] G. Attwell, "The personal learning environments - the future of elearning?" eLearning Papers, 2(1). 2007.

[4] S. Downs, "e-Learning 2.0," eLearn Magazine, 2005. Available at: http://www.elearnmag.org/subpage.cfm?section=articles\&article= $\underline{29-1}$

[5] B. Taraghi, M. Ebner, G. Till, "Personal learning environment - A conceptual study," Int. Conf. on Interactive Computer Aided Learning (ICL 2009), Villach, AT.

[6] M., van Harmelen, "Personal learning environments." Proceedings of the 6th International Conference on Advanced Learning Technologies (ICALT'06), 2006, IEEE.

[7] M.A. Chatti, Anggraeni, M. Jarke, M. Specht, and K. Maillet, "PLEM: a Web 2.0 driven Long Tail aggregator and filter for elearning." International Journal of Web Information Systems, vol 6 no. 1,2010 , pp. 5-23.

[8] S. Downes, "Personal learning environments". Keynote Presentation delivered to Interactive Technology in Education Conference , April 22, 2010, Hämeenlinna, Finland. http://www.downes.ca/presentation/245 [Nov. 19, 2010].

[9] S. Wilson, "Patterns of personal learning environments. Interactive Learning Environments", Vol. 16, No. 1, 2008, pp. $17-34$.

[10] I. Canova Calori, "Awareness for fostering serendipitous interaction in public intelligent environments." Journal of Ambient Intelligence and Smart Environments (JAISE), 2(??):8390, 2009.

[11] B Stewart, "Digital literacies 101, what MOOCs really teach," Inside Higher Education. http://tinyurl.com/bwtleek [Nov. 2, 2012].

[12] R. Williams, R. Karousou, \& J. Mackness, "Emergent Learning and Learning Ecologies in Web 2.0," International Review of Research in Open and Distance Learning, 12, 3, 2011, 39-59.

[13] N. Sclater, "Web 2.0, personal learning environments, and the future of learning management systems" (Research Bulletin, Issue 13). Boulder, CO: EDUCAUSE Center for Applied Research. 2008

[14] CISCO, "Equipping every learner for the 21st century." A white paper developed by the Centre for Strategic Education, Cisco Systems, Inc., and McKinsey \& Company. 2008. Available: http://tinyurl.com/cut5517 [Jan. 13, 2012].

[15] C. McLoughlin, and M. J. W. Lee, "Personalized and self regulated learning in the Web 2.0 era: International exemplars of innovative pedagogy using social software.” Australasian Journal of Educational Technology, 26(1), 2010, pp. 28-43.

[16] A. Couros, "Developing personal learning networks for open and social learning." In Emerging Technologies in Distance Education, G. Veletsianos (Ed.), Published by AU Press, Athabasca University, Edmonton, 2010, pp. 109-128.

[17] S. Downes, "Learning networks in practice." in Emerging Technologies for Learning (David Ley, ed). 2007. NRC 49275.

[18] R. Kop, "Information aggregation in networked learning: The human factor and serendipity." 8th Int. Conf. on Networked Learning, Maastricht, The Netherlands, April 2-4, 2012.

[19] N., Dabbagh, \& A. Kitsantas, "Personal Learning Environments, social media, and self-regulated learning: A natural formula for connecting formal and informal learning." The Internet and Higher Education, 15(1),2011, pp. 3-8.

[20] S. Schaffert \& W. Hilzensauer, "On the way towards personal learning environments: seven crucial aspects." eLearning Papers • $\mathrm{N}^{\circ}$ 9 • July $2008 \cdot$ ISSN, pp. 1887-1542.

[21] S. Wheeler, "Learning space mashups: combining web 2.0 tools to create collaborative and reflective learning spaces," Future Internet. 2009, 1(1), pp.3-13.

[22] T., Anderson, "PLEs versus LMS: Are PLEs ready for Prime time? In: Virtual Canuck -Teaching and Learning in a Net-Centric World." http://tinyurl.com/3x838q [Apr. 7, 2012].

[23] S. Wheeler, "Anatomy of PLE," http://stevewheeler.blogspot.fi/2010/07/anatomy-of-ple.html [Jul. 3, 2012].
[24] J. Mott, "Envisioning the post - LMS era: the open learning network," http://www.educause.edu/ero/article/envisioning-postlms-era-open-learning-network [Aug. 19, 2012].

[25] J. Arnold, "The WWW cabinet of curiosities: a serendipitous research tool." Journal of Education and Learning; Vol. 1, No. 2; 2012

[26] I. Buchem, "Serendipitous learning: recognizing and fostering the potential of microblogging." Formare Open Journal, February 2011 "Microblogging in Education." Accessed on 2 June 2012 from: http://tinyurl.com/ccycc58 [Jun. 2, 2012].

[27] R., Kop, "The unexpected connection: serendipity and human mediation in networked learning." Educational Technology \& Society, 15 (2), pp. 2-11.2012

[28] J. Gritton, "Of serendipity, free association and aimless browsing Do they lead to serendipitous learning?" 2007. Accessed on 15th May 2012 from: http://bit.ly/nVzteF [May 15, 2012].

[29] T. J. Sommer, "Bahramdipity and nulltiple scientific discoveries." Science and Engineering Ethics, 2001, 7(1), pp. 77-104.

[30] A. Foster, and N., Ford, "Serendipity and information seeking: an empirical study." Journal of Documentation 59(3), 2003, pp. 321340 .

[31] J. Mackness, S. Mak \& R. Williams, "The ideals and reality of participating in a mooc." Proc. 7th Int. Conf. on Networked Learning 2010, Edited by: Dirckinck-Holmfeld L, Hodgson V, Jones C, de Laat M, McConnell D \& Ryberg T. pp. 267-274.

[32] W. Reinhardt, S. Wheeler, M. Ebner, "All I need to know about twitter in education I learned in kindergarten," in Proc. Key Competencies in the Knowledge Society, 2010, pp.322-332.

[33] G. Conole, "Theory and methodology in Networked learning." Positional paper for the Networked Learning Hotseat debate, January 2010 .

[34] R. V. Kozinets, "Netnography: The marketer's secret weapon, how social media understanding drives innovation." 2010.

[35] B. Kieslinger, M. Ebner, "A qualitative approach towards discovering microblogging practices of scientists," Proc. Of Int. Conf. Interactive Collaborative Learning (ICL), 2011, pp. 51-57.

[36] M. Saadatmand, K. Kumpulainen, "Emerging technologies and new learning ecologies: learner's perceptions of learning in open and networked environments". Proc. of the 8th Int. Conf. on Networked Learning 2012, Edited by: Hodgson V, Jones C, de Laat M, McConnell D, Ryberg T \& Sloep P. pp.xxx-xxx.

[37] H. Jarche, "From observation to breakthrough", http://www.jarche.com/2012/10/from-observation-tobreakthrough/ [Nov. 1. 2012].

[38] Henry Nothhaft, Jr. "The myth of serendipity", Tech Crunch 2010. http://techcrunch.com/2010/11/27/myth-serendipity/] [Oct. 23 , 2012].

[39] W. Creixell, J. C. Losada, T. Arredondo, P. Olivares and R. M. Benito, "Serendipity in social networks," Networks and heterogeneous media, Volume 7, Number 3, September 2012 pp. 363-371.

\section{AUTHORS}

M. Saadatmand is a $\mathrm{PhD}$ candidate at the Department of Teacher Education, University of Helsinki, Helsinki, Finland. He has a Master's Degree in educational technology and currently is finalizing his doctoral thesis on open online learning. (mohsen.saadatmand@helsinki.fi).

K. Kumpulainen is a professor at the Department of Teacher Education, University of Helsinki, Helsinki, Finland. Before that she has worked as Director at the Finnish National Board of Education. (kristiina.kumpulainen@helsinki.fi).

This work was supported in part by Academy of Finland, MOTIVE Program. It is an extended and modified version of a paper presented at the International Conference on Interactive Collaborative Learning (ICL2012), held 26 - 28 September 2012, in Villach, Austria. Received 15 November 2012. Published as resubmitted by the authors 3 December 2012 